\title{
The Relationship of Emotion Intelligence, Knowledge-Sharing and Group Work Results of Vietnam Students
}

\author{
Thu Hang Le, Minh Ngoc Pham, Pham Phuong Anh Nguyen, and Linh Thi Phuong Nguyen
}

\section{ABSTRACT}

Teamwork is arguably a major aspect of university teaching as it gives students opportunities to apply their expertise to problemsolving skills, and to sharpen their skills for future jobs; to improve study outcomes, motivation, and attitudes toward learning. In addition, Emotion Intelligence (EI) and knowledge-sharing are said to have an impact on group work results. The goal of this study is to investigate the relationship between EI, knowledge-sharing, and group work results of university students. The research team conducted a survey that involved 372 students from universities majoring in economics in Hanoi, Vietnam. Research results confirm that EI has a positive effect on students' knowledge-sharing skills and group work results, and knowledge-sharing is the mediator in the relationship between $\mathrm{EI}$ and the performance of the group.

Keywords: Emotion Intelligence, Knowledge-Sharing, Group Work Result, EI.
Published Online: July 15, 2021

ISSN: $2736-4534$

DOI : $10.24018 /$ ejedu.2021.2.3.90

Thu Hang Le

National Economics of University, Vietnam.

(e-mail: lethuhang1407@gmail.com)

Minh Ngoc Pham

National Economics of University, Vietnam.

(e-mail: minhngocminhngoc15@gmail.com)

Pham Phuong Anh Nguyen

National Economics of University, Vietnam.

(e-mail: phuonganhoct229@gmail.com)

Linh Thi Phuong Nguyen

National Economics of University, Vietnam.

(e-mail: plinhkt@gmail.com)

*Corresponding Author

\section{INTRODUCTION}

Working in groups offers a variety of advantages for students because this method promotes higher-level thinking, satisfies students with the learning experience in a higher level of communication to improve self-management, making work plans, and help them understand the feelings of others [1]. Therefore, many documents confirm the benefits of group working for university students [2].

Firstly, teamwork allows students to perform work related to applying knowledge, using expertise to solve a single problem [3], [4].

Secondly, students have the opportunity to experiment and acquire new skills they need in the future. Some skills include problem-solving, friendly competition, relationshipsdeveloping, personal qualities, and creating motivation [5].

Thirdly, a positive impact of teamwork has been shown on student achievement, motivation, and attitudes toward learning [6], [7].

According to research by Gujral and Ahuja [8], the authors affirm that EI plays an important role in how team members collaborate and cooperate on the same task. At the same time, EI has a direct impact on the students' group work results in the educational environment. Besides, research by Lin [9], Bock et al [10] shows that EI has an influence on knowledgesharing ability. Individuals with high EI will easily meet the requirements such as creating, enforcing equity, and deploying exchanges among other team members. Meanwhile, by maintaining an emotional response, individuals will voluntarily and actively disseminate experimental knowledge and common knowledge to team members. Knowledge-sharing is the process of giving and receiving knowledge, exchanging ideas through discussion and deliberation to create new knowledge [11] and individual contributions contribute to improvement in team's performance [12]-[14].

With the above analysis, this study focuses on solving two goals. First, study EI's direct relationship and student group work results. Second, study the mediating role of knowledgesharing in the relationship between EI and group work results.

\section{LITERATURE REVIEW AND RESEARCH FRAMEWORK INTRODUCTION}

\section{A. Relationship between EI and Group Work Results \\ 1. Emotion Intelligence (EI)}

Emotion Intelligence (EI) has been a research topic of particular that interests many scholars over the past decades, rooted in Gardner's theory of multiple intelligence (1983). Goleman [15] defined EI as the understanding of emotion on one's own and that of others and using them in decisionmaking. Mayer and Salovey [16] defined EI as "The ability to accurately perceive, evaluate and express emotions; the 
ability to reach and/or create emotions when they think; ability to understand emotions and knowledge about emotions; and the ability to regulate emotions to promote emotional and intellectual development".

\section{EI model}

The conceptual framework that underpins this study is based on the work of Mayer and Salovey [16] concerning the four branches of the EI model:

1. Emotional Awareness

2. Emotion's Usage

3. Emotional Understanding

4. Emotional Control

Emotional Awareness is understood as the ability to self-perceive the emotions of self and that of others accurately.

Emotion's Usage is defined as the ability to use one's emotions to promote thinking, support judgment, thinking, and awareness about mood swings, leading to consideration in alternative attitudes and understanding about a change in state by using emotions to solve different problems.

Emotional Understanding is the ability to help individuals understand emotions, causes, and development of emotions, including the ability to define, distinguish types of emotions, understand the complexity of emotions as well as patterns. emotionally: loss often entails boredom, anger removes fear...

Emotional Control is the capability for the individual to control their own emotions and organize his emotions.

Previous studies have confirmed the relationship between the success of group work and EI [17], [18], Muhammad including improvement of communication [19] which increase the value of team productivity [20], increase collaboration to achieve common goals [8], provide opportunities for students to reflect and well-applied teamwork skills while doing practical exercises [19]. Therefore, the proposed research hypothesis is:

Hypothesis 1 (H1): Emotion Intelligence has a positive influence on student group work results.

B. Relationship among Knowledge-sharing, EI, and Group Work Results

\section{Relationship between knowledge-sharing and EI}

Many previous studies have mentioned the relationship between EI and knowledge-sharing [21]-[23]. Rechberg and Syed [24] studied the effect of EI on individual participation in knowledge-sharing practices. Thanks to EI, individuals are able to increase self-awareness, social awareness, and personal relationship management skills, personal emotions as a dominant factor, thus making positive or negative impacts on their knowledge processing behavior is necessary. Acquisition of knowledge is demonstrated through the individual's ability to accurately detect and interpret factors about personal emotions and surroundings. Therefore, the proposed research hypothesis is:

Hypothesis 2 (H2): Emotion Intelligence has a positive influence on knowledge-sharing.

\section{Relationship of knowledge-sharing with group work} results

Individuals working in groups can promote performance by sharing knowledge and understanding of team members' emotional expressions [11], [12]. This knowledge is created by the individual or accumulated through study and work [25], discussions, seminars, internships, and meetings [26]. Knowledge-sharing will help improve team member capabilities and improve overall performance [11], [12], [13]. Therefore, the proposed research hypothesis is:

Hypothesis 3 (H3): Knowledge-sharing has a positive influence on student group work's result

\section{Relationship of among knowledge-sharing, EI, and group work results}

After studying the studies of Dartey Baah et al [21], Polese et al [22], Tommasetti et al [23], Khalili, A. [27], Efthimiou [28], Callin and Bamford [20] the authors discovered the effect of the knowledge-sharing mediating factor in EI relationships and group work outcomes. Specifically, the Research results of Callin and Bamford [20] confirm that an effective group needs both EI and specialized knowledge, including professional skills, engineering, technology, social knowledge, and interaction through knowledge-sharing. Rechberg and Syed [24] conclude that individuals can enhance their own awareness, control their emotions to influence knowledge-sharing behavior. From there, interpersonal skills, communication, and teamwork skills will become more favorable towards the common goal. Therefore, the proposed research hypothesis is:

Hypothesis 4 (H4): The relationship between Emotion Intelligence and student group's work result is mediated by knowledge-sharing.

\section{ReSEARCH METHODOLOGY}

\section{A. Survey}

The authors inherit the scale from previous studies to build questionnaires and distribute them from July to October 2020 for 6 universities with economic majors in Hanoi. The survey questionnaire was distributed and collected 372 valid responses.

The content of the table consists of 2 contents: the first part to find out the respondent's consent to express their emotional abilities, to share knowledge and results of students' group work through the research secondary data and in-depth interviews with university students. In the second part, the authors find out the respondents' personal information about gender, year of students, frequency of working in groups. Personal information is described in Table I.

TABLE I: CHARACTERISTICS OF THE SAMPLE

\begin{tabular}{cccc}
\hline $\begin{array}{c}\text { Demographic } \\
\text { information }\end{array}$ & Frequency & $\begin{array}{c}\text { Number of } \\
\text { respondents }\end{array}$ & $\begin{array}{c}\text { Percentages } \\
(\%)\end{array}$ \\
\hline \hline \multirow{2}{*}{ Gender } & Female & 183 & 49.2 \\
& Male & 189 & 50.8 \\
& $1 \mathrm{st}$ & 52 & 14.0 \\
Year of & 2 nd & 101 & 27.2 \\
students & $3 \mathrm{rd}$ & 166 & 44.6 \\
& 4 th & 48 & 12.9 \\
& Other & 5 & 1.3 \\
Frequency of & Never & 2 & 0.5 \\
group & Rarely & 10 & 2.7 \\
working & Sometimes & 96 & 25.8 \\
& Usually & 264 & 71.0 \\
\hline \hline
\end{tabular}


The results will then be analyzed using techniques of SPSS 22.0 và AMOS 22.0 software. These tools help the research team analyze Cronbach's Alpha reliability coefficients, exploratory factor analysis (EFA), confirmatory factor analysis (CFA).

\section{B. Measures}

All scales used in the authors' research inherits from previous studies. The scales will be evaluated based on the Liker scale ( 1 - strongly disagree, 2 - disagree, 3 - neutral, 4 - agree, and 5 - strongly agree).

Emotion Intelligence (EI): The 18-item scale is developed by the research teams Mayer-Salovey [16], BarOn [30], and Goleman [31]. Emotional awareness - EU, emotional understanding - EUS and emotional control - EC.

- Emotional Awareness ( $\alpha$ 's $=0.865)$ : includes 5 items, such as self-assessment sample 'I am aware of personal emotions (happy, annoying, nervous ...) when meeting someone... " (EA1: 0.855).

- Emotional Understanding ( $\alpha$ 's = 0.776): includes 5 items, for example, self-assessment sentence 'When communicating, I know how to organize event content to make listeners feel comfortable '(EUS2: 0.723).

- Emotional Using ( $\alpha$ 's=0.888): includes 5 items, for example, the self-assessment sentence pattern 'My ability to think of new ideas is influenced by my mood (from sad to happy, there are more new ideas or vice versa ...) '(EU2: 0.833). In particular, the first observation is excluded because of the item-sum correlation less than 0.3 .

- Emotional Control ( $\alpha$ 's = 0.849): includes 3 items, such as self-assessment sentence pattern, 'I can always control my emotions in all situations.' (EC3: 0.693).

Knowledge-sharing (KS): $(\alpha$ 's=0.856) includes 6 assessment sentences designed by Lin [9], Bock et al [10]. For example, the self-assessment phrase "I am willing to share my information with my team members" (KS2: 0.675), 'I am willing to share my knowledge (Intelligence) with my teammates. '(KS3: 0.818).

The results of the group work $(\mathrm{R}):\left(\alpha^{\prime} \mathrm{s}=0.876\right)$ designed by Callin and Bamford [20] yield 6 evaluation sentences. "The team worked together to complete tasks in a timely manner." (R1: 0.711), "the team morale was positive Prompts: Appropriate support, confidence, spirit, optimism, determination" (R3: 0.647).

\section{RESULTS AND IMPLICATIONS}

Cronbach's alpha coefficients for the multiple-item EI, student group work's result and knowledge-sharing are both greater than 0.7 , indicating an acceptable level of reliability for the three scales [14]. The correlation coefficient among the variables is shown in Table II. The results indicated that EI had a positive correlation with student group work's result and knowledge-sharing ( $\mathrm{r}=0.120$ and 0.178 respectively, $\mathrm{p}<0.05)$, knowledge-sharing had a positive correlation with student group work's result $(\mathrm{r}=0.305, \mathrm{p}<0.01)$.

TABLE II: MEANS, STANDARD DEVIATIONS AND CORRELATIONS AMONG THE RELATED VARIABLES

\begin{tabular}{cccccc}
\hline \hline & Mean & Std. Deviation & EI & KS & R \\
\hline \hline EI & 3.6382 & 0.52391 & 1 & $0.498^{* *}$ & $0.514^{* *}$ \\
KS & 3.7531 & 0.65631 & $0.120^{*}$ & 1 & $0.305^{* *}$ \\
$\mathrm{R}$ & 3.9162 & 0.56482 & $0.178^{* *}$ & $0.609^{* *}$ & 1 \\
\hline \hline
\end{tabular}

In the initial model Overall fit statistics (Table III) of the measurement model are as follows: the model's fit function (Chi-Square/ df) is 1.921 which is between 1.0 and 3.0, GFI $=0.887, \mathrm{AGFI}=0.866, \mathrm{PGFI}=0.744, \mathrm{CFI}=0.940, \mathrm{PNFI}=$ $0.792, \mathrm{PCFI}=0.843, \mathrm{RMSEA}=0.050$, and $\mathrm{PCLOSE}=0.515$, suggesting support for the hypothesized model and therefore the distinctiveness of the variables in this study.

The three important indicators of convergent validity are factor loadings (standardized estimates), the average variance extracted (AVE) and composite reliability (CR). The standardized estimates of each construct range from 0.635 to 1.021 and are statistically significant (p-values). AVE ranges from 0.506 to 0.692 and $C R$ ranges from 0.829 to 0.878 . The results of standardized estimates, AVE and CR are all in the acceptable region, thereby providing support for convergent validities of constructs (Table III).

TABLE III: THE MEASUREMENT MODEL

\begin{tabular}{|c|c|c|c|c|c|}
\hline Construct & Item & $\begin{array}{c}\text { Standardized } \\
\text { estimates }\end{array}$ & $\mathrm{CR}$ & AVE & $\begin{array}{c}\mathrm{P}- \\
\text { value }\end{array}$ \\
\hline \multirow{5}{*}{ EI } & EA1 & 0.8300 & \multirow{5}{*}{0.872} & \multirow{5}{*}{0.578} & \multirow{5}{*}{0.000} \\
\hline & EA2 & 0.7510 & & & \\
\hline & EA3 & 0.8031 & & & \\
\hline & EA4 & 0.8468 & & & \\
\hline & EA5 & 0.7581 & & & \\
\hline \multirow{4}{*}{ EU } & EU2 & 0.9972 & \multirow{4}{*}{0.829} & \multirow{4}{*}{0.554} & \multirow{4}{*}{0.000} \\
\hline & EU3 & 1.0214 & & & \\
\hline & EU4 & 0.8973 & & & \\
\hline & EU5 & 0.9606 & & & \\
\hline \multirow{5}{*}{ EUS } & EUS1 & 0.9913 & \multirow{5}{*}{0.836} & \multirow{5}{*}{0.565} & \multirow{5}{*}{0.000} \\
\hline & EUS2 & 0.9302 & & & \\
\hline & EUS3 & 0.8605 & & & \\
\hline & EUS4 & 0.9002 & & & \\
\hline & EUS5 & 0.9037 & & & \\
\hline \multirow{3}{*}{$\mathrm{EC}$} & EC1 & 0.9985 & \multirow{3}{*}{0.869} & \multirow{3}{*}{0.692} & \multirow{3}{*}{0.000} \\
\hline & $\mathrm{EC} 2$ & 0.9175 & & & \\
\hline & EC3 & 0.8127 & & & \\
\hline \multirow{6}{*}{$\mathrm{KS}$} & KS1 & 0.8506 & \multirow{6}{*}{0.859} & \multirow{6}{*}{0.506} & \multirow{6}{*}{0.000} \\
\hline & KS2 & 0.8587 & & & \\
\hline & KS3 & 0.8076 & & & \\
\hline & KS4 & 0.8399 & & & \\
\hline & KS5 & 0.9323 & & & \\
\hline & KS6 & 0.8676 & & & \\
\hline \multirow{6}{*}{$\mathrm{R}$} & $\mathrm{R} 1$ & 0.7024 & \multirow{6}{*}{0.878} & \multirow{6}{*}{0.546} & \multirow{6}{*}{0.000} \\
\hline & $\mathrm{R} 2$ & 0.7328 & & & \\
\hline & R3 & 0.7606 & & & \\
\hline & $\mathrm{R} 4$ & 0.7938 & & & \\
\hline & R5 & 0.6807 & & & \\
\hline & R6 & 3.9162 & & & \\
\hline
\end{tabular}

\section{A. Hypotheses Analysis}

EI, student group work's result and knowledge-sharing to verify the hypotheses, this study adopted hierarchical regression analysis to investigate the relationship among the variables listed in Table III. In Model 1, EI had a significant positive effect on student group work's result $(\beta=0.514$, $\mathrm{p}<0.001$ ), supporting H1. EI also had a significant positive effect on knowledge-sharing $(\beta=0.498, p<0.001)$, supporting H2. In Model 2, knowledge-sharing had a significant positive effect on student group work's result $(\beta=0.609, \mathrm{p}<0.001)$, supporting H3.

The mediating effect of knowledge-sharing was in accordance with the procedures by Sveiby and Simons [12] and supported findings regarding $\mathrm{H} 1, \mathrm{H} 2$ and $\mathrm{H} 3$ which all met with the preliminary conditions for the test of this effect. Model 3 showed that the relationship between EI and student group work's result was confirmed when knowledge-sharing was added to the model $(\beta=0.281, p<0.001)$, whereas 
knowledge-sharing had a significant positive effect on student group work's result $(\beta=0.469, \mathrm{p}<0.001)$. The sig ( $\mathrm{p}$ value) value of the Sobel test is $0.000<0.05$, so knowledgesharing had a totally mediating effect on the relationship between EI and student group work's result, supporting the mediating effect. Therefore, the above results support $\mathrm{H} 4$.

TABLE IV: RESULTS OF HIERARCHICAL REGRESSION ANALYSIS

\begin{tabular}{|c|c|c|c|c|}
\hline \multirow[b]{2}{*}{ Variables } & \multicolumn{2}{|c|}{ Model 1} & \multirow[b]{2}{*}{$\begin{array}{c}\text { Model } 2 \\
\text { Student } \\
\text { group } \\
\text { work's } \\
\text { result }\end{array}$} & \multirow{2}{*}{$\begin{array}{c}\text { Model } 3 \\
\text { Student } \\
\text { group } \\
\text { work's } \\
\text { result }\end{array}$} \\
\hline & $\begin{array}{l}\text { Student } \\
\text { group } \\
\text { work's } \\
\text { result }\end{array}$ & $\begin{array}{c}\text { Knowledge- } \\
\text { sharing }\end{array}$ & & \\
\hline $\begin{array}{c}\text { Emotion } \\
\text { Intelligence }\end{array}$ & $0.514 * * *$ & $0.498 * * *$ & & $0.281 * * *$ \\
\hline $\begin{array}{l}\text { Knowledge- } \\
\text { sharing }\end{array}$ & & & $0.609 * * *$ & $0.469 * * *$ \\
\hline $\mathrm{R}^{2}$ & 0.265 & 0.248 & 0.369 & 0.430 \\
\hline
\end{tabular}

\section{CONCLUSION}

The purpose of the study is to understand the relationship between EI, student group work's result and knowledgesharing together with a mediating effect of knowledgesharing on the relationship between EI and student group work's result. All the research hypotheses are accepted with $\mathrm{p}<0.01$.

Firstly, EI is positively related to student group work's result, this conclusion is acknowledged in Tucker et al. [17], Grossman [18], Luke et al. [33], Muhammad [34]. Gujral and Ahuja [8] affirmed that EI plays an important role in the way team members cooperate and collaborate on the same task. Therefore, for the group to work smoothly and achieve high results, it is necessary to have an impact on the EI of each member in the group.

Secondly, EI positively affects knowledge-sharing. This result is consistent with some previous studies of formula Dartey Baah et al. [21], Polese et al. [22], Tommasetti et al. [23]. Acquisition of knowledge is done through the ability of individuals to perceive and process information, directly related to individual emotional factors such as emotional awareness and understanding [24].

Thirdly, knowledge-sharing has a positive relationship with student group work results. This assertion is recognized in several studies such as Jamshed and Majeed [14], Sveiby and Simons [12], Xue et al [13]. Significant evidence shows that the exchange of ideas and knowledge through discussion and consideration to create new knowledge has an impact on the contributions of each individual and will contribute to improving team performance.

Fourthly, this study confirms the mediating effect of knowledge-sharing on the relationship between EI and student group work result. The above result is aligned with the preceding study which found that perception of mediating effect of knowledge-sharing [20]-[23], [27]-[29].

The authors have based on qualitative and quantitative research to clarify the relationship between EI, knowledgesharing, and group work results. In summary, the results show that knowledge-sharing and EI have a positive impact on students' group work performance; and knowledgesharing is the intermediary between EI and group work results of students majoring in economics in Hanoi, Vietnam.

\section{REFERENCES}

[1] Hernandez, "Team learning in a marketing principles course Cooperative structures that facilitate active learning and higher level thinking," J. Mark. Educ., vol. 24, no. 1, pp. 73-85, 2002.

[2] Marin-Garcia and J. Lloret, "Improving teamwork with university engineering students. The effect of an assessment method to prevent shirking," WSEAS Trans. Adv. Eng. Educ., vol. 5, no. 1, pp. 1-11, 2008.

[3] Pineda and L. D. Lerner, "Goal attainment, satisfaction and learning from teamwork,” Team Perform. Manag. Int. J., 2006.

[4] Galbraith and F. L. Webb, "Teams that work: Preparing student teams for the workplace," Am. J. Bus. Educ. AJBE, vol. 6, no. 2, pp. 223 234, 2013.

[5] Chin, "Examining teamwork and leadership in the fields of public administration, leadership, and management," Team Perform. Manag. Int. J., 2015.

[6] Gatfield, "Examining student satisfaction with group projects and peer assessment," Assess. Eval. High. Educ., vol. 24, no. 4, pp. 365-377, 1999.

[7] Kalliath and M. Laiken, Use of teams in management education. Sage Publications Sage CA: Thousand Oaks, CA, 2006.

[8] Gujral and J. Ahuja, "Impact of emotional intelligence on teamworkA comparative study of self managed and cross functional teams," Int. J. Multidiscip. Res., vol. 1, no. 6, pp. 178-185, 2011.

[9] Lin, "Knowledge sharing and firm innovation capability: an empirical study," Int. J. Manpow., 2007.

[10] Bock, A. Kankanhalli, and S. Sharma, "Are norms enough? The role of collaborative norms in promoting organizational knowledge seeking,” Eur. J. Inf. Syst., vol. 15, no. 4, pp. 357-367, 2006.

[11] Hislop, "Mission impossible? Communicating and sharing knowledge via information technology," J. Inf. Technol., vol. 17, no. 3, pp. 165177, 2002.

[12] Sveiby and R. Simons, "Collaborative climate and effectiveness of knowledge work-an empirical study," J. Knowl. Manag., 2002.

[13] Xue, J. Bradley, and H. Liang, "Team climate, empowering leadership, and knowledge sharing," J. Knowl. Manag., 2011.

[14] Jamshed and N. Majeed, "Relationship between team culture and team performance through lens of knowledge sharing and team emotional intelligence,” J. Knowl. Manag., 2019.

[15] Goleman, Working with emotional intelligence. New York: Bantam Books, 1998.

[16] Mayer and P. Salovey, "What is emotional intelligence," Emot. Dev. Emot. Intell. Educ. Implic., vol. 3, p. 31, 1997.

[17] Tucker, J. Z. Sojka, F. J. Barone, and A. M. McCarthy, "Training tomorrow's leaders: Enhancing the emotional intelligence of business graduates," J. Educ. Bus., vol. 75, no. 6, pp. 331-337, 2000.

[18] Grossman, "Emotions at work," in Healthcare Forum Journal, 2000, vol. 43, no. 5, pp. 18-18.

[19] Stephens and A. Carmeli, "The positive effect of expressing negative emotions on knowledge creation capability and performance of project teams," Int. J. Proj. Manag., vol. 34, no. 5, pp. 862-873, 2016.

[20] McCALLIN and A. Bamford, "Interdisciplinary teamwork: is the influence of emotional intelligence fully appreciated?", J. Nurs. Manag., vol. 15, no. 4, pp. 386-391, 2007.

[21] Dartey-Baah and B. Mekpor, "The leaders' emotional intelligence," Afr. J. Econ. Manag. Stud., 2017.

[22] Polese, J. Pels, B. Tronvoll, R. Bruni, and L. Carrubbo, "A4A relationships," J. Serv. Theory Pract., 2017.

[23] Tommasetti, O. Troisi, and M. Vesci, "Measuring customer value cocreation behavior: Developing a conceptual model based on servicedominant logic," J. Serv. Theory Pract., 2017.

[24] Rechberg and J. Syed, "Appropriation or participation of the individual in knowledge management," Manag. Decis., 2014.

[25] Gibbert and H. Krause, "Practice exchange in a best practice marketplace," Knowl. Manag. Case Book Siemens Best Pract., pp. 89105, 2002.

[26] Chirico, "The creation, sharing and transfer of knowledge in family business," J. Small Bus. Entrep., vol. 21, no. 4, pp. 413-433, 2008.

[27] Khalili, "Transformational leadership and organizational citizenship behavior," Leadersh. Organ. Dev. J., 2017.

[28] Efthimiou, "Heroic ecologies: embodied heroic leadership and sustainable futures," Sustain. Account. Manag. Policy J., 2017.

[29] Bendell, N. Sutherland, and R. Little, "Beyond unsustainable leadership: critical social theory for sustainable leadership," Sustain. Account. Manag. Policy J., 2017. 
[30] Bar-On, BarOn emotional quotient inventory. Multi-health systems, 1997.

[31] Goleman, "An EI-based theory of performance," Emot. Intell. Workplace Sel. Meas. Improve Emot. Intell. Individ. Groups Organ., vol. 1, pp. 27-44, 2001.

[32] Baron and D. A. Kenny, "The moderator-mediator variable distinction in social psychological research: Conceptual, strategic, and statistical considerations.," J. Pers. Soc. Psychol., vol. 51, no. 6, p. 1173, 1986.
[33] Goodrich and M. Luke, "The experiences of school counselors-intraining in group work with LGBTQ adolescents," J. Spec. Group Work, vol. 35, no. 2, pp. 143-159, 2010.

Muhammad, "Leadership, governance and public policy implementation competencies in the broader public sector," Eur. J. Bus. Manag., vol. 6, no. 36, 2014. 